\title{
Mechanisms underpinning inattention and hyperactivity: neurocognitive support for ADHD dimensionality
}

\author{
G. A. Salum ${ }^{1,2 *}$, E. Sonuga-Barke ${ }^{3,4}$, J. Sergeant ${ }^{5}$, J. Vandekerckhove ${ }^{6}$, A. Gadelha ${ }^{1,2}$, \\ T. S. Moriyama ${ }^{1,7}$, A. S. Graeff-Martins ${ }^{1,7}$, G. G. Manfro ${ }^{1,2}$, G. Polanczyk ${ }^{1,7}$ and L. A. P. Rohde ${ }^{1,2}$ \\ ${ }^{1}$ National Institute of Developmental Psychiatry for Children and Adolescents, São Paulo, Brazil \\ ${ }^{2}$ Federal University of Rio Grande do Sul, Porto Alegre, Brazil \\ ${ }^{3}$ Southampton University, UK \\ ${ }^{4}$ Ghent University, Belgium \\ ${ }^{5}$ Vrije Universiteit, The Netherlands \\ ${ }^{6}$ University of California, USA \\ ${ }^{7}$ São Paulo University, Brazil
}

Background. Taxometric and behavioral genetic studies suggest that attention deficit hyperactivity disorder (ADHD) is best modeled as a dimension rather than a category. We extended these analyses by testing for the existence of putative ADHD-related deficits in basic information processing (BIP) and inhibitory-based executive function (IB-EF) in individuals in the subclinical and full clinical ranges. Consistent with the dimensional model, we predicted that ADHD-related deficits would be expressed across the full spectrum, with the degree of deficit linearly related to the severity of the clinical presentation.

Method. A total of 1547 children (aged 6-12 years) participated in the study. The Development and Well-Being Assessment (DAWBA) was used to classify children into groups according to levels of inattention and hyperactivity independently: (1) asymptomatic, (2) subthreshold minimal, (3) subthreshold moderate and (4) clinical ADHD. Neurocognitive performance was evaluated using a two-choice reaction time task (2C-RT) and a conflict control task (CCT). BIP and IB-EF measures were derived using a diffusion model (DM) for decomposition of reaction time (RT) and error data.

Results. Deficient BIP was found in subjects with minimal, moderate and full ADHD defined in terms of inattention (in both tasks) and hyperactivity/impulsivity dimensions (in the 2C-RT). The size of the deficit increased in a linear manner across increasingly severe presentations of ADHD. IB-EF was unrelated to ADHD.

Conclusions. Deficits in BIP operate at subclinical and clinical levels of ADHD. The linear nature of this relationship provides support for a dimensional model of ADHD in which diagnostic thresholds are defined in terms of clinical and societal burden rather than representing discrete pathophysiological states.

Received 25 May 2013; Revised 27 February 2014; Accepted 22 March 2014

Key words: ADHD, dimensionality, hyperactivity, inattention, neurocognitive, neuropsychology.

\section{Introduction}

The controversy of whether attention deficit hyperactivity disorder (ADHD) should be regarded as a category or as a dimension has been a key issue in the literature for over a decade (Carson, 1991; Clark et al. 1995). A categorical view proposes that ADHD differs qualitatively from variation in the normal range, with the discontinuity in underlying

* Address for correspondence: G. A. Salum, M.D., Ph.D., Hospital de Clínicas de Porto Alegre, Ramiro Barcelos 2350, room 2202, Porto Alegre 90035-003, Brazil.

(Email:gsalumjr@gmail.com) risk processes around the diagnostic boundary. The dimensional view, by contrast, sees ADHD differing from normality only in degree, with a spectrum of severity expressing continuity in risk-disorder relationships (Coghill \& Sonuga-Barke, 2012). In the former, diagnostic thresholds are conceptualized to reflect 'natural' boundaries linked to underlying causes; in the latter, they reflect clinical and societal burden. Although commonsense may indicate for both clinicians and researchers that ADHD might be best conceptualized as a dimension rather than a category, scientific evidence supporting commonsense reasoning has been restricted to behavioral genetic (Levy et al. 1997; Polderman et al. 2007; Larsson et al. 
2012), taxonomic (Haslam et al. 2006; Frazier et al. 2007; Marcus \& Barry, 2011; Marcus et al. 2012) and neuroimaging (Shaw et al. 2011) approaches. Studies investigating this issue from a neurocognitive perspective are lacking.

ADHD children differ from typically developing peers in a variety of cognitive domains (SonugaBarke, 2005). Deficits in inhibitory-based executive function (IB-EF; Barkley, 1997; Quay, 1997; Wood et al. 2010) and basic information processing (BIP; Sergeant, 2000; Castellanos et al. 2005; Rommelse et al. 2007; Bitsakou et al. 2008; Mulder et al. 2010) are particularly consistent among studies and are considered central to ADHD neuropsychology (Barkley, 1997; Quay, 1997; Sergeant et al. 2003; Nigg et al. 2005; Sonuga-Barke, 2005; Wood et al. 2010; Killeen et al. 2013). BIP refers to a set of lower-order cognitive processes that are involved in processing very basic information involved in almost all neurocognitive tasks such as encoding and efficiency of stimulus transmission and motor function (Parisi, 1997; Sergeant, 2000). IB-EF reflects top-down cognitive processes linked to the ability to inhibit an inappropriate prepotent or dominant response in favor of a more appropriate alternative (Barkley, 1997). BIP and IB-EF are frequently measured using forced-choice reaction time (RT) paradigms requiring a quick decision in which both accuracy and response speed are measured. In these tests, children with ADHD often respond less accurately, more slowly and have more variable RTs than their peers (Kuntsi \& Klein, 2012). However, the psychological significance of these differences are obscured by the fact that errors and RTs on these tasks are not independent and can reflect multiple interactive processes, such as stimulus encoding, processing efficiency, motor preparation and output and speed-accuracy trade-off (Ratcliff \& McKoon, 1988). Sequential sampling statistical models such as diffusion models (DMs) can differentiate between these different elements by simultaneously analyzing RTs and accuracy over time. In the current study, we extracted such DM parameter estimates to provide more interpretable assessments of BIP and IB-EF.

Previous DM analyses have found that subjects with ADHD are less efficient in basic processing efficiency, that is in the DM parameter drift rate (Huang-Pollock et al. 2012; Karalunas et al. 2012; Karalunas \& Huang-Pollock, 2013). Indeed, some studies suggest that executive deficits in ADHD may be totally attributable to underlying BIP deficits (Karalunas \& Huang-Pollock, 2013). Concurring with these findings, a previous study from our group showed that children with ADHD have deficits in encoding/motor-function and decision-making processes (Salum et al. 2014).
We therefore used the documented association between BIP deficits and ADHD subjects from our previous study to formally test competing models of ADHD (e.g. dimensional and categorical). We built on this literature to examine the presence of BIP and IB-EF across the clinical and subclinical parts of the ADHD spectrum and to test between categorical and dimensional models of the neuropsychological basis of ADHD. The categorical model predicts a discontinuity in the pattern of associations between symptom severity and cognitive impairment around the diagnostic boundary, that is deficits would be present in full ADHD cases and absent in sub-boundary cases. Therefore, we would expect a non-linear relationship between increases in symptom severity and the scale of cognitive deficits. By contrast, the dimensional model predicts no such discontinuity, with cognitive deficits present in subclinical and in clinical cases to a degree proportionate to the severity of the ADHD presentation. Thus, the symptom severity and cognitive deficit association is predicted to take a linear form.

To test these different predictions, we selected different samples of children not meeting a full ADHD diagnosis but with different levels of symptoms (asymptomatic, subthreshold minimal and subthreshold moderate) and compared these with a group of children with ADHD defined by DSM. Using this approach, we were able to test between the categorical and the dimensional models relating ADHD to BIP and IB-EF. We adopted a group-based approach rather than exploring associations across ADHD symptom levels as a continuous trait because we wanted to maintain the clinical relevance of the analysis by including a group that met the full diagnostic criteria. As currently conceptualized, ADHD is not defined simply as high levels of ADHD symptoms, but requires synthetic diagnostic rules to be met in relation to different dimensions of ADHD, age of onset restrictions and also related impairment.

In keeping with the previous literature supporting the dimensional model, our main predictions were that: (i) deficits in neurocognitive functions would be observed at subclinical and full clinical levels of ADHD and (ii) deficits would increase in a linear way across groups with increasingly severe presentations of ADHD. We selected groups excluding children with other psychiatric disorders and exposure to medication. Medication and co-morbidity have proven to affect both BIP and IB-EF in previous studies (Oosterlaan et al. 1998, 2005; Rhodes et al. 2006, 2012; Coghill et al. 2007; Chamberlain et al. 2011; Swanson et al. 2011; Wang et al. 2013). Therefore, this sampling strategy provided a strong design for testing this specific hypothesis. It decreases the possibility that 
a categorical nature would be revealed by factors influencing cognition in ways not specifically linked to ADHD symptom severity.

\section{Method}

\section{Participants}

The sample is part of a large community school-based study of children aged 6 to 12 years from 57 schools in two Brazilian cities: Porto Alegre $(n=22)$ and São Paulo $(n=35)$. The ethics committee of the University of São Paulo approved the study. We obtained written consent from parents of all participants, and verbal assent from all children.

During the screening phase at their school registry day, 9937 informants were interviewed using the Family History Survey (FHS; Weissman et al. 2000). From this pool, we recruited two subgroups using a random-selection $(n=958)$ and high-risk group selection procedure $(n=1514)$, resulting in a total sample of 2512 subjects (for further details, see Salum et al. 2013). From these 2512 subjects, 2002 (74\%) had data available for the tasks used in this study. Subjects who did not perform the tasks did not differ from those who did regarding psychopathology (all $p>0.05$; data available upon request). A total of 144 subjects were excluded for poor task compliance, but again no differences were detected between them and the remaining sample regarding psychopathology (all $p>0.05$; data not shown).

The aim of the current study was to select from the remaining sample $(n=1858)$ specific groups of participants with different levels of symptom severity across the spectrum of ADHD symptoms (from non-clinical to clinical) but without co-morbidity with other psychiatric disorders. The ADHD section of the Development and Well-Being Assessment (DAWBA; Goodman et al. 2000) (no skipping rules) was used to assess inattention and hyperactivity/impulsivity in the total sample. Each of the 18 ADHD symptoms has a three-option response scale 'No more than other', 'A little more than others' and 'A lot more than others', representing a score of 0,1 and 2 respectively. Groups were constructed based on similar symptom cut-offs suggested by previous studies exploring subthreshold ADHD (Faraone et al. 2006; Shaw et al. 2011). Therefore, we selected overlapping hierarchically defined sets of groups as follows.

\section{Inattention}

(1) Asymptomatic: randomly selected subjects, scoring 0 on inattentive symptoms; (2) subthreshold minimal symptoms: subjects scoring from 1 to 5 on the inattentive symptoms scale (maximum of two full ADHD symptoms); (3) subthreshold moderate symptoms: subjects scoring from 6 to 11 on inattentive symptoms (maximum of five full ADHD symptoms in typically developing children); (4) predominantly inattentive ADHD subtype $(n=36)$ or a combined ADHD subtype $(n=17)$ (full ADHD DSM-IV diagnoses including impairment).

\section{Hyperactivity/impulsivity}

(1) Asymptomatic: randomly selected subjects, scoring 0 on the hyperactive/impulsive symptom scale; (2) subthreshold minimal symptoms: subjects scoring from 1 to 5 on the hyperactive/impulsive symptom scale (maximum of two full ADHD symptoms); (3) subthreshold moderate symptoms: subjects scoring from 6 to 11 on hyperactive/impulsive symptom scale (maximum of five full ADHD symptoms in typically developing children); (4) predominantly hyperactive/impulsive ADHD subtype $(n=15)$ or a combined ADHD subtype ( $n=17)$ (full ADHD DSM-IV diagnoses). Inattentive and hyperactive/impulsive groups were created independently, and hyperactivity/impulsivity was allowed to vary freely within the inattentive group, and vice versa.

We excluded from all analyses participants who had ever received any psychiatric medication with or without a psychiatric diagnosis $(n=74,4 \%$; of whom 36 had ADHD), with an IQ below $70(n=36 ; 1.8 \%)$, co-morbid conduct/oppositional disorder $(n=127 ; 6.8 \%)$, anxiety $(n=100 ; 5.4 \%)$, depression $(n=64 ; 3.5 \%)$, mania $(n=3$; $0.2 \%)$, psychoses $(n=1 ; 0.1 \%)$, pervasive developmental $(n=9 ; 0.6 \%)$, tics $(n=15 ; 0.8 \%)$ and eating $(n=8$; $0.5 \%$ ) disorders.

\section{Psychiatric diagnosis}

Our diagnosis was based on the DAWBA (Goodman et al. 2000), a structured interview administered to biological parents by trained lay-interviewers. The DAWBA is a reliable and widely used psychiatric instrument translated into 22 languages. A comparison of levels of agreement for ADHD between the DAWBA and the Child and Adolescent Psychiatric Assessment (CAPA) and between the DAWBA and the Diagnostic Interview Schedule for Children (DISC) resulted in moderate agreement (0.49 and 0.57 respectively), similar to the $\kappa$ value of 0.52 obtained by Angold et al. (2012) when comparing CAPA and DISC. The DAWBA is well suited for epidemiological research, given that it is shorter than alternative interviews. Nine psychiatrists performed the rating procedures. All were trained and supervised by a senior child psychiatrist. A second child psychiatrist rated a total of 200 interviews and the between-rater $\kappa$ values for ADHD was high (0.72). 


\section{Neurocognitive tasks}

Two tasks were used to assess BIP and IB-EF: a simple two-choice reaction time task (2C-RT) and a conflict control task (CCT; Hogan et al. 2005). The 2C-RT measures the ability of the participant to perform basic perceptual decisions about the direction an arrow on the screen is pointing. It has minimal executive component. A total of 100 arrow stimuli were presented, half requiring a left and half requiring a right button press. The CCT builds on the 2C-RT and includes a second inhibitory executive component requiring participants to occasionally suppress a dominant tendency to respond to the actual direction of an arrow and to initiate a response indicating the opposite direction. This requirement was indicated by a change in the color of the arrow (a 'conflict' effect). There were 75 congruent trials with green arrows (participants had to press the button indicating the actual direction of the arrow) and 25 incongruent trials, when red arrows were presented (and participants had to respond in the opposite direction to that indicated by the arrows presented). These two tasks were used to derive BIP variables using DMs (2C-RT and CCT) and IB-EF measured in the context of BIP deficits.

\section{Deriving indices of $\mathrm{BIP}$}

BIP variables were derived from DM analysis (Ratcliff \& McKoon, 1988; White et al. 2010) from both 2C-RT and CCT data. The parameters of this model provide information about: processing efficiency [drift rate $(v)$, the rate at which an individual is able to acquire information to make a forced choice response; that is the neural signal-to-noise ratio], speed-accuracy trade-off [boundary separation $(a)$, response caution or impulsive response style] and encoding/motor function [nondecision time (Ter), the time it takes to complete all other information processes not involved in stimulus discrimination] (Huang-Pollock et al. 2012). Both processing efficiency and encoding/motor function fluctuate from trial to trial in the course of the experiment, also providing parameters of BIP variability $(Q$ and $e$ respectively).

Data points in the DM analysis that are outliers (outside the range of normal observations) or likely to represent contaminants (random guesses and fast guesses) were detected and filtered out using exponentially weighted moving average (EWMA). Further details about these methods can be found in Vandekerckhove \& Tuerlinckx (2007). A total of 36 participants $(1.6 \%)$ had more than $50 \%$ of missing/outlier responses and were excluded from the analysis. In addition, 108 (4.3\%) were excluded because of failures in estimating the parameters with the Markov chain Monte Carlo method (Vandekerckhove \& Tuerlinckx,
2007). There were no between-group differences in the number of non-included subjects in the analyses (all $p$ values $>0.05$ ).

\section{Estimating IB-EF (taking account of BIP)}

IB-EF was estimated by subtracting mean drift rates (i.e. processing efficiency) of incongruent trials from mean drift rates of congruent trials (White et al. 2010). This model assumes that, on the incongruent trials of CCT, there is a 'conflict effect'; that is an initial accumulation of evidence towards the wrong boundary (the conflict effect), which is followed for an accumulation of evidence towards the correct boundary. Congruent trials do not have conflict and therefore the subtraction (incongruent minus congruent) provides a way of estimating the IB-EF more reliably and taking account of BIP (i.e. above and beyond deficits in BIP).

\section{Statistical analysis}

To investigate our first hypothesis, we performed a series of MANCOVAs using BIP DM variables derived from $2 \mathrm{C}-\mathrm{RT}$ and $\mathrm{CCT}$. The results from the MANCOVAs and IB-EF derived measures from the CCT were further decomposed with ANCOVAs and between-group differences were analyzed using two specific contrasts: (1) differences from asymptomatic individuals and (2) differences from clinically defined ADHD subjects. All models controlled for site, gender, age and IQ. We tested linear, quadratic and cubic trends among the means of the four groups in the ANCOVAs for all BIP and IB-EF parameters using polynomial contrasts to test our second hypothesis. Groups were formed to have a very similar range of increments of symptoms from the asymptomatic group.

All variables were $z$ transformed and normalized using the van den Waerden transformation (Lehmann, 1975). Effect sizes were defined in terms of percentage of explained variance and 1, 9 and 25\% were defined respectively as small, medium and large effects corresponding to $0.01,0.06$ and 0.14 partial eta square $\left(\eta_{\mathrm{p}}^{2}\right)$ values (Cohen, 1988). DM analysis was implemented using hierarchical DMs for two-choice response times. Details about the estimation of DM outcome variables can be found elsewhere (Vandekerckhove et al. 2011). All tests were two-tailed, with an $\alpha$ value of 0.05 .

\section{Results}

Sample characteristics are given in Table 1. Groups did not differ in terms of gender (all $p$ values $>0.05$ ), and age differences were minimal. Analyses for inattentive 
Table 1. Sample description and classical task measures

\begin{tabular}{|c|c|c|c|c|c|c|c|c|}
\hline & \multicolumn{2}{|c|}{$\begin{array}{l}\text { Asymptomatic } \\
(n=229)(19.3 \%)\end{array}$} & \multicolumn{2}{|c|}{$\begin{array}{l}\text { Subthreshold } \\
\text { minimal }(n=590) \\
(49.8 \%)\end{array}$} & \multicolumn{2}{|c|}{$\begin{array}{l}\text { Subthreshold } \\
\text { moderate } \\
(n=312)(26.4 \%)\end{array}$} & \multicolumn{2}{|c|}{$\begin{array}{l}\text { ADHD } \\
\text { inattentive/ } \\
\text { combined }(n=53) \\
(4.5 \%)\end{array}$} \\
\hline & Mean & S.D. & Mean & S.D. & Mean & S.D. & Mean & S.D. \\
\hline Age (years) & 9.7 & 2.0 & 9.9 & 2.0 & 9.9 & 2.0 & 9.5 & 1.8 \\
\hline IQ score & 106.0 & 15.7 & 102.9 & 16.0 & 102.0 & 16.1 & 100.0 & 16.8 \\
\hline SES score & 21.3 & 4.9 & 20.2 & 4.8 & 19.6 & 4.8 & 20.2 & 5.6 \\
\hline \multicolumn{9}{|l|}{ 2C-RT } \\
\hline$\%$ Correct & 82.3 & 14.1 & 79.1 & 15.5 & 77.7 & 14.2 & 71.4 & 16.1 \\
\hline$\%$ Outlier & 2.3 & 2.5 & 2.6 & 2.7 & 2.8 & 2.5 & 4.3 & 3.8 \\
\hline Mean RT & 478.2 & 105.6 & 486.4 & 111.5 & 501.0 & 118.3 & 504.0 & 104.3 \\
\hline S.D. RT & 161.6 & 77.0 & 179.2 & 79.6 & 187.8 & 79.2 & 227.8 & 97.7 \\
\hline \multicolumn{9}{|l|}{ CCT Congruent } \\
\hline$\%$ Correct & 78.4 & 16.1 & 73.2 & 17.7 & 71.5 & 18.9 & 63.4 & 19.8 \\
\hline$\%$ Outlier & 1.9 & 4.2 & 2.0 & 2.7 & 2.4 & 5.5 & 1.7 & 1.9 \\
\hline Mean RT & 558.3 & 121.7 & 556.3 & 122.9 & 573.4 & 128.5 & 561.5 & 123.3 \\
\hline S.D. RT & 162.6 & 57.3 & 172.8 & 63.9 & 182.1 & 68.5 & 204.2 & 84.1 \\
\hline \multicolumn{9}{|l|}{ CCT Incongruent } \\
\hline$\%$ Correct & 65.7 & 19.5 & 59.8 & 20.6 & 57.9 & 21.6 & 55.8 & 18.0 \\
\hline$\%$ Outlier & 0.6 & 1.6 & 0.8 & 2.0 & 0.6 & 1.6 & 1.5 & 3.2 \\
\hline Mean RT & 684.6 & 154.1 & 677.4 & 164.3 & 695.3 & 166.6 & 675.7 & 140.2 \\
\hline S.D. RT & 168.5 & 80.4 & 189.8 & 85.5 & 200.9 & 95.4 & 233.0 & 110.8 \\
\hline ADHD Total & 0.7 & 1.3 & 5.4 & 3.4 & 13.0 & 4.3 & 25.4 & 5.4 \\
\hline Hyperactivity/impulsivity & 0.7 & 1.3 & 2.7 & 2.8 & 5.2 & 3.6 & 10.3 & 4.6 \\
\hline \multirow[t]{2}{*}{ Inattentive } & 0.0 & 0.0 & 2.7 & 1.3 & 7.8 & 1.5 & 15.2 & 1.9 \\
\hline & $n$ & $\%$ & $n$ & $\%$ & $n$ & $\%$ & $n$ & $\%$ \\
\hline \multirow[t]{3}{*}{ Gender } & 104 & 45.4 & 300 & 50.8 & 166 & 53.2 & 30 & 56.6 \\
\hline & \multicolumn{2}{|c|}{$\begin{array}{l}\text { Asymptomatic } \\
(n=227)(19.8 \%)\end{array}$} & \multicolumn{2}{|c|}{$\begin{array}{l}\text { Subthreshold } \\
\text { minimal } \\
(n=658)(57.6 \%)\end{array}$} & \multicolumn{2}{|c|}{$\begin{array}{l}\text { Subthreshold } \\
\text { moderate } \\
(n=225)(19.7 \%)\end{array}$} & \multicolumn{2}{|c|}{$\begin{array}{l}\text { ADHD } \\
\text { hyperactive/ } \\
\text { combined } \\
(n=32)(2.8 \%)\end{array}$} \\
\hline & Mean & S.D. & Mean & S.D. & Mean & S.D. & Mean & S.D. \\
\hline Age (years) & 9.9 & 2.1 & 9.9 & 2.0 & 9.4 & 1.9 & 9.8 & 1.9 \\
\hline IQ (score) & 104.9 & 15.1 & 102.4 & 16.2 & 104.1 & 16.7 & 101.1 & 18.3 \\
\hline SES (score) & 21.1 & 5.0 & 20.1 & 4.7 & 20.1 & 4.7 & 20.5 & 5.7 \\
\hline \multicolumn{9}{|l|}{ 2C-RT } \\
\hline$\%$ Correct & 81.8 & 14.8 & 79.5 & 14.8 & 76.5 & 14.9 & 69.7 & 16.7 \\
\hline$\%$ Outlier & 2.3 & 2.6 & 2.5 & 2.7 & 3.0 & 2.6 & 4.2 & 3.4 \\
\hline Mean RT & 481.4 & 106.6 & 491.5 & 114.3 & 498.3 & 112.3 & 503.0 & 96.1 \\
\hline S.D. RT & 165.7 & 79.4 & 179.1 & 80.7 & 192.1 & 78.8 & 230.9 & 98.9 \\
\hline \multicolumn{9}{|l|}{ CCT Congruent } \\
\hline$\%$ Correct & 77.1 & 16.8 & 73.8 & 18.0 & 70.6 & 17.3 & 67.1 & 20.0 \\
\hline$\%$ Outlier & 1.9 & 4.0 & 2.2 & 4.5 & 2.0 & 2.4 & 1.4 & 1.1 \\
\hline Mean RT & 560.4 & 115.4 & 562.9 & 127.1 & 567.9 & 126.5 & 571.5 & 105.2 \\
\hline S.D. RT & 164.9 & 59.7 & 176.0 & 66.5 & 180.7 & 65.1 & 204.9 & 82.1 \\
\hline \multicolumn{9}{|l|}{ CCT Incongruent } \\
\hline$\%$ Correct & 64.1 & 20.6 & 60.2 & 21.0 & 56.8 & 20.4 & 59.5 & 17.5 \\
\hline$\%$ Outlier & 0.7 & 1.8 & 0.8 & 1.8 & 0.8 & 1.9 & 0.8 & 1.9 \\
\hline Mean RT & 683.2 & 162.0 & 683.8 & 161.4 & 699.8 & 173.3 & 686.7 & 161.3 \\
\hline S.D. RT & 171.9 & 81.6 & 191.7 & 88.8 & 196.0 & 87.1 & 221.8 & 111.7 \\
\hline
\end{tabular}


Table 1 (cont.)

\begin{tabular}{|c|c|c|c|c|c|c|c|c|}
\hline & \multicolumn{2}{|c|}{$\begin{array}{l}\text { Asymptomatic } \\
(n=227)(19.8 \%)\end{array}$} & \multicolumn{2}{|c|}{$\begin{array}{l}\text { Subthreshold } \\
\text { minimal } \\
(n=658)(57.6 \%)\end{array}$} & \multicolumn{2}{|c|}{$\begin{array}{l}\text { Subthreshold } \\
\text { moderate } \\
(n=225)(19.7 \%)\end{array}$} & \multicolumn{2}{|c|}{$\begin{array}{l}\text { ADHD } \\
\text { hyperactive/ } \\
\text { combined } \\
(n=32)(2.8 \%)\end{array}$} \\
\hline & Mean & S.D. & Mean & S.D. & Mean & S.D. & Mean & S.D. \\
\hline ADHD Total & 0.8 & 1.4 & 5.9 & 3.6 & 13.6 & 4.0 & 28.1 & 3.9 \\
\hline Hyperactivity/impulsivity & 0.0 & 0.0 & 2.6 & 1.3 & 7.6 & 1.5 & 14.8 & 1.7 \\
\hline \multirow[t]{2}{*}{ Inattentive } & 0.8 & 1.4 & 3.3 & 3.0 & 6.0 & 3.3 & 13.3 & 3.1 \\
\hline & $n$ & $\%$ & $n$ & $\%$ & $n$ & $\%$ & $n$ & $\%$ \\
\hline Gender & 104 & 46 & 327 & 49.8 & 126 & 56 & 17 & 53.1 \\
\hline
\end{tabular}

ADHD, Attention deficit hyperactivity disorder; IQ, intelligence quotient; SES, socio-economic status; 2C-RT, two-choice reaction time task; CCT, conflict control task; S.D., standard deviation.

Outliers defined as RTs $<100 \mathrm{~ms}$ or 3 s.D.s above the subject's mean (for descriptive purposes).

and hyperactive ADHD symptoms are depicted in Tables 2 and 3 respectively.

For inattention, we found diminished processing efficiency $(v)$ in children with minimal inattentive symptoms in both tasks compared to asymptomatic children. In addition to lower processing efficiency, those with moderate levels of inattention also had a higher trial-to-trial variability in encoding/motor function $(Q)$ in both tasks compared to asymptomatic participants. In addition to the deficits presented by the moderate group, full ADHD inattentive/combined participants also had higher variability in processing efficiency $(E)$ and faster encoding/motor function (Ter) in the 2C-RT compared to asymptomatic individuals. For all between-group differences, we found a significant linear trend supporting a dose-response relationship between inattentive symptoms and BIP (Table 2, Fig. 1). No between-group differences in IB-EF were found (Table 2).

With respect to hyperactivity/impulsivity, the minimal hyperactivity group had diminished processing efficiency $(v)$ when compared to the asymptomatic group, a pattern similar to that seen in the moderate symptoms group and the group with full-blown ADHD in the 2C-RT task. Those with moderate symptoms and those with ADHD also had a faster encoding/motor function $(Q)$ only in the 2C-RT. The overall MANCOVA for the CCT was not significant and therefore no further ANCOVAs for the CCT were performed (Table 3, Fig. 1). Again, all between-group differences had a significant linear trend and therefore support a dose-response relationship between hyperactive symptoms and BIP. No between-group differences were detected for IB-EF (Table 3).

Additional analyses revealed that our results were unaffected by controlling for subthreshold oppositional defiant disorder (ODD) symptoms based on the Child Behavior Checklist (CBCL; Krol et al. 2006) (Supplementary Tables S1 and S2). In addition, in a supplementary linear model using ADHD as a continuous variable, contrasts revealed that, for all significant associations between ADHD and neurocognitive variables, a linear trend could be detected and no other higher-order link function was statistically significant (Supplementary Table S3). An exception is the encoding/motor function (Ter) in the 2C-RT, where no trend was detected.

\section{Discussion}

In this study, we were able to demonstrate that deficits in information processing were found in subjects with minimal, moderate and clinical ADHD for both inattention (in both tasks) and hyperactivity/impulsive dimensions (in the 2C-RT). No significant associations emerged for IB-EF. Crucially, these trends followed a linear function and therefore there was no evidence for a discontinuity in the neurocognitive association around the categorical boundary. The current study provides evidence that deficient processing efficiency is a key element in ADHD neuropsychology as the syndrome meeting the full criteria and is also strongly implicated in both inattention and hyperactivity problems even at minimal levels. These results therefore demonstrate that neuropsychological deficits operate at several levels of the ADHD symptom spectrum and provide neurocognitive support for a dimensional model of ADHD.

We have demonstrated the value of the DM perspective for understanding the origins of the inaccurate, slow and variable performance in ADHD subjects, which indicates impairments in the basic processing 
Table 2. Post-hoc ANCOVAs showing differences between groups of inattention in diffusion model (DM) parameters for the two-choice reaction time task (2C-RT) and the conflict control task (CCT)

\begin{tabular}{|c|c|c|c|c|c|c|c|c|c|c|c|c|c|c|c|}
\hline & \multicolumn{8}{|c|}{ Symptoms of inattention } & \multirow{2}{*}{\multicolumn{7}{|c|}{ ANCOVA }} \\
\hline & \multirow{2}{*}{\multicolumn{2}{|c|}{ Asymptomatic }} & \multirow{2}{*}{\multicolumn{2}{|c|}{$\begin{array}{l}\text { Subthreshold } \\
\text { minimal }\end{array}$}} & \multirow{2}{*}{\multicolumn{2}{|c|}{$\begin{array}{l}\text { Subthreshold } \\
\text { moderate }\end{array}$}} & \multirow{2}{*}{\multicolumn{2}{|c|}{$\begin{array}{l}\text { ADHD } \\
\text { inattentive/ } \\
\text { combined }\end{array}$}} & & & & & & & \\
\hline & & & & & & & & & \multirow[b]{2}{*}{$F_{3,1084}$} & \multirow[b]{2}{*}{$p$ value } & \multirow[b]{2}{*}{$\eta_{\mathrm{p}}^{2}$} & \multirow[b]{2}{*}{ Significant contrasts } & \multicolumn{3}{|l|}{ Trend } \\
\hline & Mean & S.E. & Mean & S.E. & Mean & S.E. & Mean & S.E. & & & & & Linear & Quadratic & Cubic \\
\hline \multicolumn{16}{|l|}{ BIP (2C-RT) } \\
\hline$Q$ & -0.116 & 0.063 & -0.045 & 0.039 & 0.163 & 0.053 & 0.112 & 0.126 & 4.883 & 0.002 & 0.013 & Asym $<$ Mod & 0.038 & 0.433 & 0.106 \\
\hline Ter & 0.158 & 0.067 & 0.032 & 0.042 & 0.041 & 0.057 & -0.334 & 0.134 & 3.609 & 0.013 & 0.01 & Asym $>$ ADHD; ADHD $<$ Min, Mod & 0.001 & 0.133 & 0.046 \\
\hline$a$ & -0.092 & 0.067 & 0.014 & 0.041 & -0.016 & 0.057 & 0.285 & 0.133 & 2.221 & 0.084 & 0.006 & & & & \\
\hline$e$ & -0.127 & 0.069 & 0.022 & 0.042 & 0.012 & 0.058 & 0.318 & 0.137 & 3.031 & 0.029 & 0.008 & Asym $<$ ADHD; ADHD $<$ Min, Mod & 0.004 & 0.35 & 0.073 \\
\hline$v$ & 0.227 & 0.063 & 0.031 & 0.039 & -0.056 & 0.054 & -0.395 & 0.127 & 7.739 & $<0.001$ & 0.021 & $\begin{array}{l}\text { Asym }>\text { Min, Mod, ADHD; } \\
\text { ADHD<Min, Mod }\end{array}$ & $<0.001$ & 0.354 & 0.14 \\
\hline \multicolumn{16}{|l|}{$\mathrm{BIP}(\mathrm{CCT})$} \\
\hline$Q$ & -0.138 & 0.06 & -0.005 & 0.037 & 0.098 & 0.051 & 0.279 & 0.12 & 4.705 & 0.003 & 0.013 & Asym $<$ Mod, ADHD & 0.001 & 0.747 & 0.635 \\
\hline $\operatorname{Ter}(\mathrm{c})$ & 0.113 & 0.067 & -0.015 & 0.041 & 0.073 & 0.057 & -0.06 & 0.133 & 1.255 & 0.288 & 0.003 & & & & \\
\hline$a$ & -0.078 & 0.069 & 0.014 & 0.042 & 0.072 & 0.058 & 0.022 & 0.137 & 0.929 & 0.426 & 0.003 & & & & \\
\hline$e$ & -0.099 & 0.069 & 0.016 & 0.042 & 0.027 & 0.058 & 0.016 & 0.137 & 0.819 & 0.483 & 0.002 & & & & \\
\hline$v(\mathrm{c})$ & 0.185 & 0.067 & 0.022 & 0.042 & -0.071 & 0.057 & -0.333 & 0.134 & 5.089 & 0.002 & 0.014 & Asym $>$ Min, Mod, ADHD; ADHD $<$ Min & $<0.001$ & 0.551 & 0.361 \\
\hline \multicolumn{16}{|l|}{ IB-EF (CCT) } \\
\hline$v(\mathrm{c})-v(\mathrm{i})$ & 0.009 & 0.068 & -0.052 & 0.042 & -0.015 & 0.057 & 0.241 & 0.135 & 1.512 & 0.21 & 0.004 & & & & \\
\hline
\end{tabular}

ADHD, Attention deficit hyperactivity disorder (predominantly inattentive or combined subtypes); BIP, basic information processing; IB-EF, inhibitory-based executive function; S.E., standard error; Asym, asymptomatic; Min, minimal; Mod, moderate; $Q$, trial-to-trial variability in Ter; Ter, mean non-decision time (encoding/motor function); a, boundary separation (speed/accuracy trade-off); $e$, trial-to-trial variability in $v$; $v$, mean drift rate (processing efficiency); (c), congruent trial; (i) incongruent trial.

MANCOVAs: BIP (2C-RT) $F_{15,3246}=3.07 / p<0.001 / \eta_{\mathrm{p}}^{2}=0.014 ; \mathrm{BIP}$ (CCT) $F_{15,3246}=2.63 / p=0.001 / \eta_{\mathrm{p}}^{2}=0.012$.

Polynomial contrasts: differences between asymptomatic and non-clinical groups are in italics.

Estimated marginal means for $z$ scores (corrected for age and IQ).

Analysis repeated only in the randomly selected subjects resulted in very similar results.

Bold values indicate statistically significant results. 
Table 3. Post-hoc ANCOVAs showing differences between groups of hyperactivity/impulsivity in diffusion model (DM) parameters for the two-choice reaction time task (2C-RT) and the conflict control task $(\mathrm{CCT})$

\begin{tabular}{|c|c|c|c|c|c|c|c|c|c|c|c|c|c|c|c|}
\hline & \multicolumn{8}{|c|}{ Symptoms of hyperactivity/impulsivity } & \multirow{2}{*}{\multicolumn{7}{|c|}{ ANCOVA }} \\
\hline & \multirow{2}{*}{\multicolumn{2}{|c|}{ Asymptomatic }} & \multirow{2}{*}{\multicolumn{2}{|c|}{$\begin{array}{l}\text { Subthreshold } \\
\text { minimal }\end{array}$}} & \multirow{2}{*}{\multicolumn{2}{|c|}{$\begin{array}{l}\text { Subthreshold } \\
\text { moderate }\end{array}$}} & \multirow{2}{*}{\multicolumn{2}{|c|}{$\begin{array}{l}\text { ADHD } \\
\text { hyperactive/ } \\
\text { combined }\end{array}$}} & & & & & & & \\
\hline & & & & & & & & & \multirow[b]{2}{*}{$F_{3,1044}$} & \multirow[b]{2}{*}{$p$ value } & \multirow[b]{2}{*}{$\eta_{\mathrm{p}}^{2}$} & \multirow[b]{2}{*}{ Significant contrasts } & \multicolumn{3}{|l|}{ Trend } \\
\hline & Mean & S.E. & Mean & S.E. & Mean & S.E. & Mean & S.E. & & & & & Linear & Quadratic & Cubic \\
\hline \multicolumn{16}{|l|}{ BIP (2C-RT) } \\
\hline$Q$ & -0.033 & 0.064 & -0.029 & 0.037 & 0.06 & 0.064 & 0.255 & 0.164 & 1.381 & 0.247 & 0.004 & & & & \\
\hline Ter & 0.175 & 0.067 & 0.04 & 0.039 & -0.056 & 0.068 & -0.372 & 0.173 & 3.907 & 0.009 & 0.011 & $\begin{array}{l}\text { Asym }>\text { Mod, ADHD; } \\
\text { ADHD }<\text { Min }\end{array}$ & 0.002 & 0.369 & 0.385 \\
\hline$a$ & -0.064 & 0.067 & -0.007 & 0.039 & 0.047 & 0.068 & 0.314 & 0.173 & 1.57 & 0.195 & 0.004 & & & & \\
\hline$e$ & -0.084 & 0.069 & -0.029 & 0.04 & -0.066 & 0.069 & 0.38 & 0.177 & 2.079 & 0.101 & 0.006 & & & & \\
\hline$v$ & 0.189 & 0.063 & 0.027 & 0.037 & -0.087 & 0.064 & -0.521 & 0.164 & 6.946 & $<0.001$ & 0.02 & $\begin{array}{l}\text { Asym }>\text { Min, Mod, ADHD; } \\
\text { ADHD }<\text { Min, Mod }\end{array}$ & $<0.001$ & 0.154 & 0.194 \\
\hline \multicolumn{16}{|l|}{ BIP (CCT) } \\
\hline$Q$ & -0.044 & 0.061 & 0.001 & 0.035 & 0.126 & 0.061 & 0.121 & 0.157 & & & & & & & \\
\hline $\operatorname{Ter}(\mathrm{c})$ & 0.135 & 0.067 & 0.038 & 0.039 & 0.016 & 0.067 & -0.147 & 0.172 & & & & & & & \\
\hline$a$ & -0.037 & 0.068 & 0.003 & 0.04 & 0.007 & 0.068 & 0.076 & 0.175 & & & & & & & \\
\hline$e$ & -0.001 & 0.068 & -0.029 & 0.04 & 0.155 & 0.069 & 0.061 & 0.176 & & & & & & & \\
\hline$v(\mathrm{c})$ & 0.172 & 0.068 & 0.017 & 0.04 & -0.035 & 0.069 & -0.356 & 0.175 & & & & & & & \\
\hline \multicolumn{16}{|l|}{ IB-EF (CCT) } \\
\hline$v(\mathrm{c})-v(\mathrm{i})$ & -0.044 & 0.067 & -0.027 & 0.039 & -0.076 & 0.068 & 0.286 & 0.173 & 10.281 & 0.279 & 0.004 & & & & \\
\hline
\end{tabular}

ADHD, Attention deficit hyperactivity disorder (predominantly hyperactive/impulsive or combined subtypes); IB-EF, inhibitory-based executive function; BIP, basic information processing; S.E., standard error; Asym, asymptomatic; Min, minimal; Mod, moderate; $Q$, trial-to-trial variability in Ter; Ter, mean non-decision time (encoding/motor function); $a$, boundary separation (speed/accuracy trade-off); $e$, trial-to-trial variability in $v$; $v$, mean drift rate (processing efficiency); (c), congruent trial; (i) incongruent trial.

MANCOVAs: BIP (2C-RT) $F_{15,3126}=2.07 / p=0.009 / \eta_{\mathrm{p}}^{2}=0.010$; BIP (CCT) $F_{15,3126}=1.56 / p=0.077 / \eta_{\mathrm{p}}^{2}=0.007$.

Polynomial contrasts: differences between asymptomatic and non-clinical groups are in italics.

Estimated marginal means for $z$ scores (corrected for age and IQ).

Analysis repeated only in the randomly selected subjects resulted in very similar results.

Bold values indicate statistically significant results. 

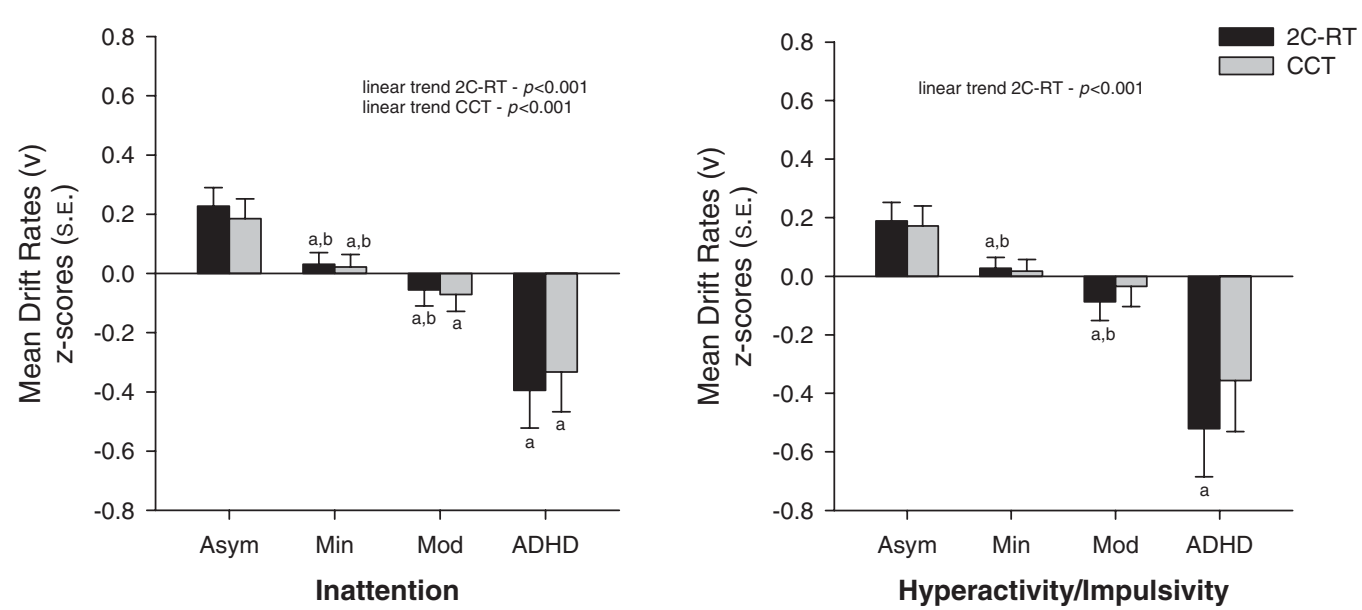

Fig. 1. Between-group differences in mean drift rates $(v)$ in the two-choice reaction time task (2C-RT) and the conflict control task (CCT) for inattention and hyperactivity/impulsivity symptoms. For the CCT, mean drift rates from congruent trials were used. Asym, asymptomatic; Min, minimal; Mod, moderate; ADHD, attention deficit hyperactivity disorder; S.E., standard error. ${ }^{a}$ Significant differences from typically developing children (TDC). ${ }^{\mathrm{b}}$ Significant differences from ADHD.

of information, particularly processing efficiency. Our results are in agreement with a growing body of literature indicating that differences in inhibitory function and other executive measures become non-significant after controlling for baseline measures of BIP (Rommelse et al. 2007; Karalunas \& Huang-Pollock, 2013), or following the introduction of incentives (Konrad et al. 2000; Slusarek et al. 2001; Kuntsi et al. 2009), and contradict inhibitory theories (Barkley, 1997; Quay, 1997; Wood et al. 2010). Given empirical evidence supporting the association between ADHD and BIP, we postulate that these neurocognitive processes are indicators of underlying ADHD neural dysfunction. Our results suggest that neural dysfunctions related to basic processing deficits are present across the ADHD spectrum even where only minimal levels of symptoms are present.

Other evidence for dimensionality arises from several sources. Psychometric studies have used several statistical techniques such as latent class analysis (Hudziak et al. 1998; Neuman et al. 1999), factor mixture models (Lubke et al. 2009; Ranby et al. 2012) and different taxonomic approaches (Haslam et al. 2006; Frazier et al. 2007; Marcus \& Barry, 2011; Marcus et al. 2012). Behavioral genetics studies also support dimensionality (Levy et al. 1997; Polderman et al. 2007; Larsson et al. 2012). Our results are in agreement with other studies that directly investigated etiological and pathophysiological markers of ADHD. Evidence from epidemiological studies (Scahill et al. 1999), structural neuroimaging studies (Shaw et al. 2011), clinical trials (Rapoport et al. 1980; Surman et al. 2010) and personality traits (Cho et al. 2009; Faraone et al. 2009) suggest similar patterns of effects between subthreshold and clinical cases.
This evidence that ADHD is best seen as a dimension rather than a category has potentially important clinical implications. Of note, we underscore the implications to our understanding of the etiology of ADHD. Dimensional phenotypes cannot arise from a single dichotomous causal factor and are most typically the result of an interaction of multiple etiological factors (Haslam, 1997). In addition, the clinical dilemma relating to where to put the threshold designating the categorical diagnosis (Matte et al. 2012) is inherent to a dimensional approach. Pragmatically, we will still need practical decision rules for clinical purposes and the 'thresholds' decision will need to be addressed for ADHD, as in hypertension and levels of cholesterol. Therefore, focusing on defining these 'thresholds' is a crucial step for us to better stratify risk and start doing rational stepped care.

Our study has some limitations. First, other scales, such as the Strengths and Weaknesses of ADHD Symptoms and Normal Behavior (SWAN), that have a more appropriate normal distribution of its scores in the population could have been more sensitive to between-group differences in inattention and hyperactivity (Polderman et al. 2007). Second, our analyses were limited to the evaluation of BIP and IB-EF and the results do not necessarily imply that ADHD is a continuous disorder per se. Other neurocognitive domains, such as temporal processing and delay aversion, might be associated with a discontinuity within the ADHD spectrum. Nevertheless, our study shows that, for those specific measures, there is a clear linear relationship with symptom severity. Third, because of sample size issues we were not able to investigate different levels of the spectrum inside the clinical group, and a post-hoc analysis revealed that our study might 
have been underpowered to detect between-group differences in some BIP variables and in IB-EF. Our study also has notable strengths. It has a strong design to account for the impact of co-morbid problems, medication profiles and referral bias. Furthermore, all the effects reported are above and beyond effects of age, gender, IQ and investigational site.

In conjunction with accumulating evidence, our findings suggest that research in neurobiology of ADHD may benefit from a change in focus from extreme group comparisons to dimensional designs (Frazier et al. 2007). This approach may even facilitate scientific discoveries on the neurobiology of inattention and/or hyperactivity/impulsivity problems.

\section{Supplementary material}

For supplementary material accompanying this paper visit http://dx.doi.org/10.1017/S0033291714000919.

\section{Acknowledgments}

We thank the children and families for their participation, which made this research possible; the other members of the high-risk cohort research team (E. C. Miguel, R. Affonseca-Bressan, M. C. do Rosário, A. C. Tamanaha, P. Pan, P. G. de Alvarenga and H. Brentani); the collaborators for the neuropsychological evaluation (B. S. Scarpato, S. L. R. do Valle and C. Araújo); R. Goodman for his research support regarding the DAWBA instrument procedures; and B. Fleitlich-Bilyk for her clinical supervision.

This work is supported by the National Institute of Developmental Psychiatry for Children and Adolescents, a science and technology institute funded by the Conselho Nacional de Desenvolvimento Científico e Tecnológico (CNPq; National Council for Scientific and Technological Development; grant no. 573974/ 2008-0) and the Fundação de Amparo à Pesquisa do Estado de São Paulo (FAPESP; Research Support Foundation of the State of São Paulo; grant no. 2008/ 57896-8).

\section{Declaration of Interest}

G. A. Salum is in receipt of a CAPES/FAPERGS postdoctoral scholarship and declares no potential conflicts of interest. E. Sonuga-Barke is a member of an advisory board to Shire, Flynn Pharma, UCB Pharma and AstraZeneca. He has served as speaker and consultant for Shire and UCB Pharma. He receives/has received current/recent research support from Janssen Cilag, Shire, Qbtech and Flynn Pharma, and conference support from Shire. J. Sergeant is a member of an advisory board to Lilly and Shire. He has received research funding from Lilly, and speaker fees from Lilly, Janssen-Cilag, Novartis and Shire. J. Vandekerckhove declares no potential conflicts of interest. A. Gadelha and T. S. Moriyama are in receipt of CAPES Ph.D. scholarships and receive continuous medical education support from Astra Zeneca, Eli-Lilly and JanssenCilag. A. S. Graeff-Martins is in receipt of a $\mathrm{CNPq}$ post-doctoral fellowship and declares no potential conflicts of interest. G. G. Manfro receives research support from Brazilian government institutions (CNPQ, FAPERGS and FIPE-HCPA) and declares no potential conflicts of interest. G. V. Polanczyk has served as a speaker and/or consultant to Eli-Lilly, Novartis and Shire Pharmaceuticals, has developed educational material for Janssen-Cilag, and receives unrestricted research support from Novartis and CNPq. L. A. P. Rohde was on the speakers' bureau and/or acted as consultant for Eli-Lilly, Janssen-Cilag, Novartis and Shire in the past 3 years. He also received travel awards (air tickets and hotel costs) from Novartis and Janssen-Cilag in 2010 for taking part in two child psychiatric meetings. The ADHD and Juvenile Bipolar Disorder Outpatient Programs chaired by L. A. P. Rohde received unrestricted educational and research support from the pharmaceutical companies Abbott, Eli-Lilly, Janssen-Cilag, Novartis and Shire in the past 3 years.

\section{References}

Angold A, Erkanli A, Copeland W, Goodman R, Fisher PW, Costello EJ (2012). Psychiatric diagnostic interviews for children and adolescents: a comparative study. Journal of the American Academy of Child and Adolescent Psychiatry 51, 506-517.

Barkley RA (1997). Behavioral inhibition, sustained attention, and executive functions: constructing a unifying theory of ADHD. Psychological Bulletin 121, 65-94.

Bitsakou P, Psychogiou L, Thompson M, Sonuga-Barke EJ (2008). Inhibitory deficits in attention-deficit/hyperactivity disorder are independent of basic processing efficiency and IQ. Journal of Neural Transmission 115, 261-268.

Carson RC (1991). Dilemmas in the pathway of the DSM-IV. Journal of Abnormal Psychology 100, 302-307.

Castellanos FX, Sonuga-Barke EJ, Scheres A, Di Martino A, Hyde C, Walters JR (2005). Varieties of attention-deficit/ hyperactivity disorder-related intra-individual variability. Biological Psychiatry 57, 1416-1423.

Chamberlain SR, Robbins TW, Winder-Rhodes S, Muller U, Sahakian BJ, Blackwell AD, Barnett JH (2011). Translational approaches to frontostriatal dysfunction in attention-deficit/hyperactivity disorder using a computerized neuropsychological battery. Biological Psychiatry 69, 1192-1203.

Cho SC, Kim BN, Kim JW, Rohde LA, Hwang JW, Chungh DS, Shin MS, Lyoo IK, Go BJ, Lee SE, Kim HW 
(2009). Full syndrome and subthreshold attention-deficit/ hyperactivity disorder in a Korean community sample: comorbidity and temperament findings. European Child and Adolescent Psychiatry 18, 447-457.

Clark LA, Watson D, Reynolds S (1995). Diagnosis and classification of psychopathology: challenges to the current system and future directions. Annual Review of Psychology 46, 121-153.

Coghill D, Sonuga-Barke EJ (2012). Annual research review: categories versus dimensions in the classification and conceptualisation of child and adolescent mental disorders - implications of recent empirical study. Journal of Child Psychology and Psychiatry, and Allied Disciplines 53, 469-489.

Coghill DR, Rhodes SM, Matthews K (2007). The neuropsychological effects of chronic methylphenidate on drug-naive boys with attention-deficit/hyperactivity disorder. Biological Psychiatry 62, 954-962.

Cohen J (1988). Statistical Power Analysis for the Behavioral Sciences. Lawrence Erlbaum Associates: Hillsdale, NJ.

Faraone SV, Biederman J, Doyle A, Murray K, Petty C, Adamson JJ, Seidman L (2006). Neuropsychological studies of late onset and subthreshold diagnoses of adult attention-deficit/hyperactivity disorder. Biological Psychiatry 60, 1081-1087.

Faraone SV, Kunwar A, Adamson J, Biederman J (2009). Personality traits among ADHD adults: implications of late-onset and subthreshold diagnoses. Psychological Medicine 39, 685-693.

Frazier TW, Youngstrom EA, Naugle RI (2007). The latent structure of attention-deficit/hyperactivity disorder in a clinic-referred sample. Neuropsychology 21, 45-64.

Goodman R, Ford T, Richards H, Gatward R, Meltzer H (2000). The Development and Well-Being Assessment: description and initial validation of an integrated assessment of child and adolescent psychopathology. Journal of Child Psychology and Psychiatry, and Allied Disciplines 41, 645-655.

Haslam N (1997). Evidence that male sexual orientation is a matter of degree. Journal of Personality and Social Psychology 73, 862-870.

Haslam N, Williams B, Prior M, Haslam R, Graetz B, Sawyer M (2006). The latent structure of attention-deficit/ hyperactivity disorder: a taxometric analysis. Australian and New Zealand Journal of Psychiatry 40, 639-647.

Hogan AM, Vargha-Khadem F, Kirkham FJ, Baldeweg T (2005). Maturation of action monitoring from adolescence to adulthood: an ERP study. Developmental Science 8, 525-534.

Huang-Pollock CL, Karalunas SL, Tam H, Moore AN (2012). Evaluating vigilance deficits in ADHD: a meta-analysis of CPT performance. Journal of Abnormal Psychology 121, 360-371.

Hudziak JJ, Heath AC, Madden PF, Reich W, Bucholz KK, Slutske W, Bierut LJ, Neuman RJ, Todd RD (1998). Latent class and factor analysis of DSM-IV ADHD: a twin study of female adolescents. Journal of the American Academy of Child and Adolescent Psychiatry 37, 848-857.

Karalunas SL, Huang-Pollock CL (2013). Integrating impairments in reaction time and executive function using a diffusion model framework. Journal of Abnormal Child Psychology 41, 837-850.

Karalunas SL, Huang-Pollock CL, Nigg JT (2012). Decomposing attention-deficit/hyperactivity disorder (ADHD)-related effects in response speed and variability. Neuropsychology 26, 684-694.

Killeen PR, Russell VA, Sergeant JA (2013). A behavioral neuroenergetics theory of ADHD. Neuroscience and Biobehavioral Reviews 37, 625-657.

Konrad K, Gauggel S, Manz A, Scholl M (2000). Lack of inhibition: a motivational deficit in children with attention deficit/hyperactivity disorder and children with traumatic brain injury. Child Neuropsychology 6, 286-296.

Krol NP, De Bruyn EE, Coolen JC, van Aarle EJ (2006). From CBCL to DSM: a comparison of two methods to screen for DSM-IV diagnoses using CBCL data. Journal of Clinical Child and Adolescent Psychology 35, 127-135.

Kuntsi J, Klein C (2012). Intraindividual variability in ADHD and its implications for research of causal links. Current Topics in Behavioral Neurosciences 9, 67-91.

Kuntsi J, Wood AC, van der Meere J, Asherson P (2009). Why cognitive performance in ADHD may not reveal true potential: findings from a large population-based sample. Journal of the International Neuropsychological Society 15, 570-579.

Larsson H, Anckarsater H, Rastam M, Chang Z, Lichtenstein P (2012). Childhood attention-deficit hyperactivity disorder as an extreme of a continuous trait: a quantitative genetic study of 8,500 twin pairs. Journal of Child Psychology and Psychiatry, and Allied Disciplines 53, 73-80.

Lehmann EL (1975). Nonparametrics: Statistical Methods Based on Ranks. Holden-Day: San Francisco, CA.

Levy F, Hay DA, McStephen M, Wood C, Waldman I (1997). Attention-deficit hyperactivity disorder: a category or a continuum? Genetic analysis of a large-scale twin study. Journal of the American Academy of Child and Adolescent Psychiatry 36, 737-744.

Lubke GH, Hudziak JJ, Derks EM, van Bijsterveldt TC, Boomsma DI (2009). Maternal ratings of attention problems in ADHD: evidence for the existence of a continuum. Journal of the American Academy of Child and Adolescent Psychiatry 48, 1085-1093.

Marcus DK, Barry TD (2011). Does attention-deficit/ hyperactivity disorder have a dimensional latent structure? A taxometric analysis. Journal of Abnormal Psychology 120, 427-442.

Marcus DK, Norris AL, Coccaro EF (2012). The latent structure of attention deficit/hyperactivity disorder in an adult sample. Journal of Psychiatric Research 46, 782-789.

Matte B, Rohde LA, Grevet EH (2012). ADHD in adults: a concept in evolution. Attention Deficit and Hyperactivity Disorders 4, 53-62.

Mulder MJ, Bos D, Weusten JM, van Belle J, van Dijk SC, Simen P, van Engeland H, Durston S (2010). Basic impairments in regulating the speed-accuracy tradeoff predict symptoms of attention-deficit/hyperactivity disorder. Biological Psychiatry 68, 1114-1119. 
Neuman RJ, Todd RD, Heath AC, Reich W, Hudziak JJ, Bucholz KK, Madden PA, Begleiter H, Porjesz B, Kuperman S, Hesselbrock V, Reich T (1999). Evaluation of ADHD typology in three contrasting samples: a latent class approach. Journal of the American Academy of Child and Adolescent Psychiatry 38, 25-33.

Nigg JT, Willcutt EG, Doyle AE, Sonuga-Barke EJ (2005). Causal heterogeneity in attention-deficit/hyperactivity disorder: do we need neuropsychologically impaired subtypes? Biological Psychiatry 57, 1224-1230.

Oosterlaan J, Logan GD, Sergeant JA (1998). Response inhibition in $\mathrm{AD} / \mathrm{HD}, \mathrm{CD}$, comorbid $\mathrm{AD} / \mathrm{HD}+\mathrm{CD}$, anxious, and control children: a meta-analysis of studies with the stop task. Journal of Child Psychology and Psychiatry, and Allied Disciplines 39, 411-425.

Oosterlaan J, Scheres A, Sergeant JA (2005). Which executive functioning deficits are associated with $\mathrm{AD} / \mathrm{HD}, \mathrm{ODD} / \mathrm{CD}$ and comorbid AD/HD+ODD/CD? Journal of Abnormal Child Psychology 33, 69-85.

Parisi D (1997). Artificial life and higher level cognition. Brain and Cognition 34, 160-184.

Polderman TJ, Derks EM, Hudziak JJ, Verhulst FC, Posthuma D, Boomsma DI (2007). Across the continuum of attention skills: a twin study of the SWAN ADHD rating scale. Journal of Child Psychology and Psychiatry, and Allied Disciplines 48, 1080-1087.

Quay HC (1997). Inhibition and attention deficit hyperactivity disorder. Journal of Abnormal Child Psychology 25, 7-13.

Ranby KW, Boynton MH, Kollins SH, McClernon FJ, Yang C, Fuemmeler BF (2012). Understanding the phenotypic structure of adult retrospective ADHD symptoms during childhood in the United States. Journal of Clinical Child and Adolescent Psychology 41, 261-274.

Rapoport JL, Buchsbaum MS, Weingartner H, Zahn TP, Ludlow C, Mikkelsen EJ (1980). Dextroamphetamine. Its cognitive and behavioral effects in normal and hyperactive boys and normal men. Archives of General Psychiatry 37, 933-943.

Ratcliff R, McKoon G (1988). A retrieval theory of priming in memory. Psychological Review 95, 385-408.

Rhodes SM, Coghill DR, Matthews K (2006). Acute neuropsychological effects of methylphenidate in stimulant drug-naive boys with ADHD II-broader executive and non-executive domains. Journal of Child Psychology and Psychiatry, and Allied Disciplines 47, 1184-1194.

Rhodes SM, Park J, Seth S, Coghill DR (2012).

A comprehensive investigation of memory impairment in attention deficit hyperactivity disorder and oppositional defiant disorder. Journal of Child Psychology and Psychiatry, and Allied Disciplines 53, 128-137.

Rommelse NN, Altink ME, de Sonneville LM, Buschgens CJ, Buitelaar J, Oosterlaan J, Sergeant JA (2007). Are motor inhibition and cognitive flexibility dead ends in ADHD? Journal of Abnormal Child Psychology 35, 957-967.

Salum GA, Mogg K, Bradley BP, Gadelha A, Pan P, Tamanaha AC, Moriyama T, Graeff-Martins AS,
Jarros RB, Polanczyk G, do Rosario MC, Leibenluft E, Rohde LA, Manfro GG, Pine DS (2013). Threat bias in attention orienting: evidence of specificity in a large community-based study. Psychological Medicine 43, 733-745.

Salum GA, Sergeant J, Sonuga-Barke E, Vandekerckhove J, Gadelha A, Pan PM, Moriyama TS, Graeff-Martins AS, de Alvarenga PG, do Rosario MC, Manfro GG, Polanczyk G, Rohde LA (2014). Specificity of basic information processing and inhibitory control in attention deficit hyperactivity disorder. Psychological Medicine 44, 617-631.

Scahill L, Schwab-Stone M, Merikangas KR, Leckman JF, Zhang H, Kasl S (1999). Psychosocial and clinical correlates of ADHD in a community sample of school-age children. Journal of the American Academy of Child and Adolescent Psychiatry 38, 976-984.

Sergeant J (2000). The cognitive-energetic model: an empirical approach to attention-deficit hyperactivity disorder. Neuroscience and Biobehavioral Reviews 24, 7-12.

Sergeant JA, Geurts H, Huijbregts S, Scheres A, Oosterlaan J (2003). The top and the bottom of ADHD: a neuropsychological perspective. Neuroscience and Biobehavioral Reviews 27, 583-592.

Shaw P, Gilliam M, Liverpool M, Weddle C, Malek M, Sharp W, Greenstein D, Evans A, Rapoport J, Giedd J (2011). Cortical development in typically developing children with symptoms of hyperactivity and impulsivity: support for a dimensional view of attention deficit hyperactivity disorder. American Journal of Psychiatry 168, 143-151.

Slusarek M, Velling S, Bunk D, Eggers C (2001). Motivational effects on inhibitory control in children with ADHD. Journal of the American Academy of Child and Adolescent Psychiatry 40, 355-363.

Sonuga-Barke EJ (2005). Causal models of attention-deficit/ hyperactivity disorder: from common simple deficits to multiple developmental pathways. Biological Psychiatry 57, 1231-1238.

Surman C, Hammerness P, Petty C, Doyle R, Chu N, Gebhard N, Williams C, Biederman J (2010). Atomoxetine in the treatment of adults with subthreshold and/or late onset attention-deficit hyperactivity disorder-not otherwise specified (ADHD-NOS): a prospective open-label 6-week study. CNS Neuroscience and Therapeutics 16, 6-12.

Swanson J, Baler RD, Volkow ND (2011). Understanding the effects of stimulant medications on cognition in individuals with attention-deficit hyperactivity disorder: a decade of progress. Neuropsychopharmacology 36, 207-226.

Vandekerckhove J, Tuerlinckx F (2007). Fitting the Ratcliff diffusion model to experimental data. Psychonomic Bulletin and Review 14, 1011-1026.

Vandekerckhove J, Tuerlinckx F, Lee MD (2011). Hierarchical diffusion models for two-choice response times. Psychological Methods 16, 44-62.

Wang GJ, Volkow ND, Wigal T, Kollins SH, Newcorn JH, Telang F, Logan J, Jayne M, Wong CT, Han H, Fowler JS, 
Zhu W, Swanson JM (2013). Long-term stimulant treatment affects brain dopamine transporter level in patients with attention deficit hyperactive disorder. PloS One 8, e63023.

Weissman MM, Wickramaratne P, Adams P, Wolk S, Verdeli H, Olfson M (2000). Brief screening for family psychiatric history: the family history screen. Archives of General Psychiatry 57, 675-682.
White CN, Ratcliff R, Vasey MW, McKoon G (2010). Using diffusion models to understand clinical disorders. Journal of Mathematical Psychology 54, 39-52.

Wood AC, Buitelaar J, Rijsdijk F, Asherson P, Kuntsi J (2010). Rethinking shared environment as a source of variance underlying attention-deficit/hyperactivity disorder symptoms: comment on Burt (2009). Psychological Bulletin 136, 331-340. 